\title{
The potential for emergence of Chagas disease in the United States
}

\author{
Rebecca Click Lambert ${ }^{1}$, Korine N. Kolivras ${ }^{1}$, Lynn M. Resler ${ }^{1}$, Carlyle C. Brewster ${ }^{2}$, Sally \\ L. Paulson ${ }^{2}$ \\ ${ }^{1}$ Department of Geography, Virginia Polytechnic Institute and State University (Virginia Tech), 115 Major \\ Williams Hall, Blacksburg, VA 24061, USA; ${ }^{2}$ Department of Entomology, Virginia Polytechnic Institute \\ and State University (Virginia Tech), 216A Price Hall, Blacksburg, VA 24061, USA
}

\begin{abstract}
To determine the risk for Chagas disease (American trypanosomiasis) in the United States, the characteristics that make the triatomine vector effective and the areas most at risk for transmission were delineated. In addition, the status of Chagas disease awareness among physicians in areas with a potential risk for the disease was determined. A geographical information system (GIS) was used to analyze three triatomine species within the United States known to harbor Trypanosoma cruzi and that exhibit qualities of domesticity. An analysis of the minimum temperature threshold for increased triatomine activity delineates the current population at increased risk, and by incorporating temperature predictions for 2030, the population at risk under a future climate scenario was also delineated. Considering both environmental and social factors, a vignette-based physician survey, based on the results of the GIS analysis, was used to gauge the level of awareness of Chagas disease within the delineated higher risk range. The current area at increased risk for Chagas disease includes much of the southern United States, and the higher risk range is expected to expand into the central United States based upon the $1^{\circ} \mathrm{C}\left(1.8^{\circ} \mathrm{F}\right)$ increase in temperature predicted by the Intergovernmental Panel on Climate Change (IPCC) by the year 2030. Survey results indicate a limited consideration of Chagas disease during differential diagnosis, illustrating that the low number of Chagas disease cases discovered in the United States may be attributable to a lack of disease awareness as opposed to a lack of disease threat. This study combines GIS and survey analyses to evaluate the role that temperature variability and disease awareness among physicians play in the potential emergence of Chagas disease in the United States. This approach indicates that there is a potential for Chagas disease to emerge in the United States.
\end{abstract}

Keywords: Chagas disease, risk maps, geographical information systems, physician survey, vector-borne disease.

\section{Introduction}

Chagas disease (also known as American trypanosomiasis) is endemic in Central and South America, and the disease agent, Trypanosoma cruzi, primarily spreads to humans as a result of blood feeding by the triatomine vector, also known as the "kissing bug" (CDC, 2006). In the United States,

Corresponding author:

Korine N. Kolivras

Department of Geography

Virginia Polytechnic Institute and State University (Virginia Tech)

115 Major Williams Hall Blacksburg, VA 24061, USA

Tel. +1 540231 5514; Fax +1 5402312089

E-mail: korine@vt.edu triatomines have been found in proximity to humans, indicating an opportunity for the emergence of Chagas disease. There have only been six autochthonous (locally acquired) cases diagnosed in the United States since 1955 (Woody and Woody, 1955; Anonymous, 1956; Betz et al., 1984; Schiffler et al., 1984; Navin et al., 1985; Ochs et al., 1996; Herwaldt et al., 2000; Dorn et al., 2007). However, given the increase in the domestic presence of the vector in close proximity to humans, the possibility of future temperature increases, and changing habitation to areas within the vector's range, the potential exists for the disease to become established in the United States. 
The potential for the emergence of Chagas disease in the United States presents an example of the way in which disparate factors can affect disease dispersion. The triatomine's activity level is affected by temperature, and physicians are often the first to diagnose and respond to an emerging disease threat. Additionally, the literature indicates that cases beyond the six recorded so far are likely to have gone undiagnosed, indicating a need to evaluate physician awareness (Kirchhoff et al., 1987; Kirchhoff, 1993; Holbert et al., 1995; Leiby et al., 2000, 2002; Zayas et al., 2001; Kirchhoff et al., 2006; Dorn et al., 2007). Through the use of geographical information system (GIS) and survey analyses, this study examines the role that climate conditions (temperature) and disease awareness among physicians can play in the potential emergence of Chagas disease in the United States.

Increased globalization and migration have contributed to the emergence of a number of infectious diseases in recent decades. Specifically, in the medical field, global travel, increased urbanization, and suburbanization have played a role in the emergence of the severe acute respiratory syndrome (SARS), dengue fever, and Lyme disease (Haggett, 1994; Cooke and Shapiro, 2003). Additionally, there are indications that climate change particularly contributes to the spread of parasitic diseases into new locations. For example, the consequences of climate variability and change have been pointed out for schistosomiasis in the north of China (Yang et al., 2006), and are already evident in the case of malaria, which has become established at higher elevations in Africa in recent years (Epstein et al., 1998).

Given that physicians may be the first to recognize a newly emerged disease as cases present themselves in a hospital or in a doctor's office (Cooke and Shapiro, 2003), gauging Chagas disease awareness might provide a useful measure of the potential for Chagas to emerge in the United States. We specifically concentrated our efforts on the area deemed at highest risk for Chagas transmission based on temperature. While studies have examined the potential for Chagas disease emergence in specific regions of the United States (Peterson et al., 2002; Beard et al., 2003), no study has evaluated the potential across the country as a whole by examining both climatic factors and physician awareness. Our approach aims to do this and methodologically, it combines GIS and survey analyses as a way to more completely evaluate the potential for disease emergence. Two important factors support the potential emergence of Chagas disease in the United States and guide our research objectives: the vector is established and, with climate variability and change, it may increase contact with humans (Lent and Wygodzinsky, 1979); and immigrants carrying T. cruzi have migrated to the United States from endemic areas (Kirchhoff et al., 1987).

This study is built on the theoretical frameworks of landscape epidemiology and disease ecology within medical geography. The three main factors of disease ecology include the environment, human behaviour, and population characteristics (Meade and Earickson, 2005). Complimentary to all three factors of the disease ecology approach is landscape epidemiology, which defines a natural disease nidus as the locale where a disease maintains continued circulation (Meade and Earickson, 2005). With these frameworks, we have aimed to bridge the gap between the triatomine's biogeographical range and awareness of the disease among physicians.

Our specific objectives were:

(i) to delineate the areas that are at higher risk for Chagas disease transmission in the United States due to the temperature-induced increase in activity of three triatomine species that exhibit qualities of domesticity; and

(ii) to determine the level of Chagas disease awareness among physicians in regions defined as being at higher risk for disease transmission.

Figure 1 serves as a template for the research presented here and is based upon the frameworks described above. 


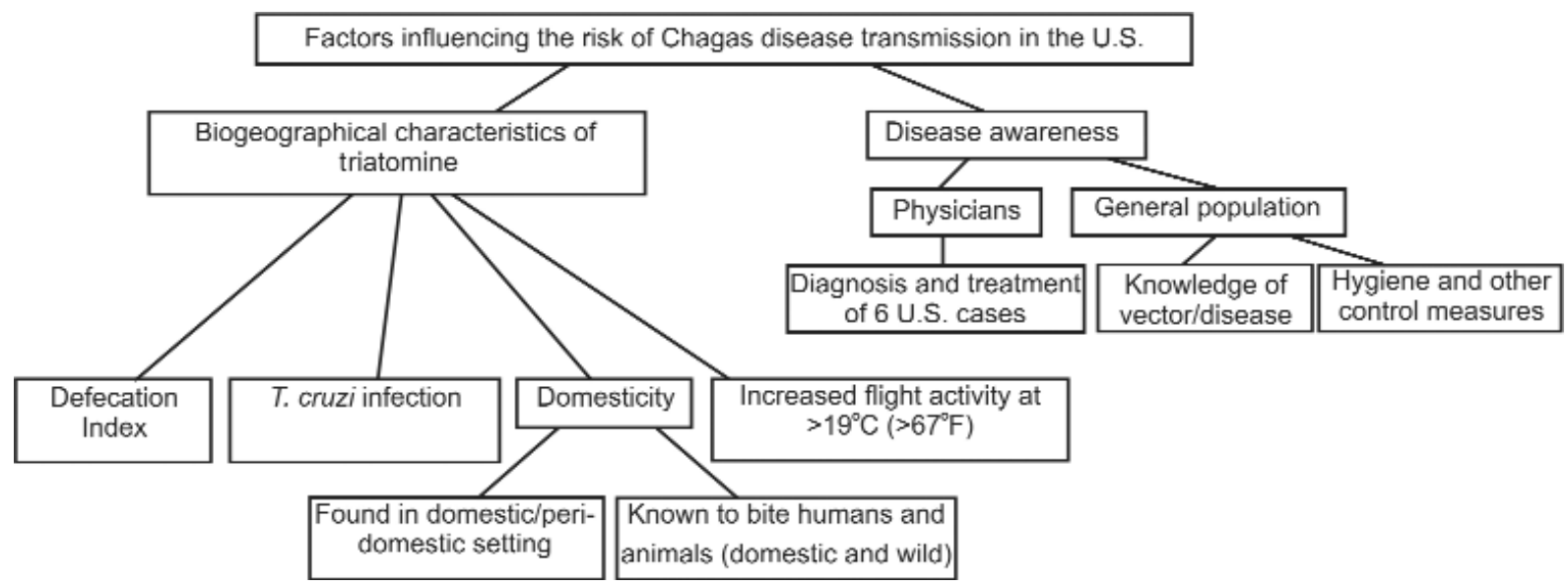

Fig. 1. Schematic defining variables for Chagas disease risk in the United States. Topics of focus in this study are domesticity and its components, T. cruzi infection, increased flight activity, and physician awareness.

\section{Background}

\section{Triatomine biogeography}

The range of the triatomine in the United States covers twenty-six states and Triatoma sanguisuga, T. lecticularia, and T. protracta, with the largest ranges in the country (Usinger, 1944; Lent and Wygodzinsky, 1979), have been reported in and around human habitations (Sjogren and Ryckman, 1966; Lent and Wygodzinsky, 1979; Navin et al., 1985; Herwaldt et al., 2000; Beard et al., 2003). Temperature, rate of defecation, prevalence of vector infectivity, and degree of domesticity play important roles in Chagas disease transmission. Regarding temperature, the minimum threshold for T. cruzi transmission is estimated to be $18^{\circ} \mathrm{C}\left(64^{\circ} \mathrm{F}\right)$ and higher temperatures reportedly increase pathogen development in the triatomine; however, temperatures greater than $38^{\circ} \mathrm{C}\left(100^{\circ} \mathrm{F}\right)$ become lethal to the pathogen (IPCC, 2001). Increased triatomine movement in warmer temperatures may result in triatomines entering the home, thus creating an opportunity for human contact with the disease vector. The risk maps created in this study incorporate biogeographical and climatological factors to depict the current and predicted higher risk range for Chagas disease in the United States.
In the context of disease ecology, investigating changes in a vector's range and habitat can gauge the vector's proximity to humans and quantify disease risk. Wood (1938) described the northward range expansion of $T$. protracta in California, but since that time, research on the triatomine's range has been limited in the United States with the exception of modeling the species' range in parts of Texas (Peterson et al., 2002; Beard et al., 2003). Modeling efforts have mapped the triatomine range in much of Latin America (Abad-Franch et al., 2001; Costa et al., 2002; Peterson et al., 2002; Guzman-Tapia et al., 2005; López-Cárdenas et al., 2005; Bustamante et al., 2007). In particular, Peterson et al. (2002) applied the genetic algorithm for rule-set prediction (GARP) model to the T. gerstaeckeri species' range in Mexico to evaluate the environmental characteristics under which the disease agent and vector thrive. Similarly, a regional analysis in Guatemala utilized environmental factors and data from field collections to determine the Chagas disease vector's primary habitat range (Bustamante et al., 2007). The broadscale study presented here fills a gap in research on the potential for Chagas disease emergence in the United States by using a GIS to analyze the current and potential triatomine range within the country.

A significant component of Chagas disease transmission is the prevalence of infection in local vector 
populations (Usinger, 1944; Kagan et al., 1966). Although the studies are somewhat dated, examinations of $T$. protracta and T. sanguisuga samples in the United States reveal a T. cruzi infection rate of 20\% (Usinger, 1944) and 6\% (Kagan et al., 1966), respectively. Another important consideration is the efficiency with which the triatomine transmits the trypanosome. If the bug defecates while consuming a blood meal, or shortly thereafter, the chances of disease transmission via the bite wound are greater (Kagan et al., 1966). Delayed defecation by the triatomine species in the United States limits the incidence of disease transmission during feeding (Kagan et al., 1966; Lent and Wygodzinsky, 1979). However, the risk of disease transmission to humans via feces may be possible through contaminated food or the mucous membranes if hygienic practices are not followed (CDC, 2006).

When a vector bites a human, it illustrates the domesticity of some triatomine species. Despite the generally sylvatic nature of the triatomine species in the United States (Kagan et al., 1966; Ryckman, 1984; Herwaldt et al., 2000; Beard et al., 2003), and a lack of a suitable habitat in most homes within the country (Zeledón, 1974), studies throughout the Americas and within the United States report numerous cases of sylvatic species biting humans when an opportunity is present. Triatomines can enter a dwelling through an unscreened open window, which may be exacerbated by an attraction to lights that increases the triatomine's lure to the domestic dwelling (Usinger, 1944; Sjogren and Ryckman, 1966; Wood and Wood, 1967; Lent and Wygodzinsky, 1979; Monroy et al., 2003; VazquezProkopec et al., 2004, 2006). Upon entering a home, triatomines often go undetected because they generally feed at night and are nocturnal by nature (Lent and Wygodzinsky, 1979; Schofield, 1979; Navin et al., 1985; Herwaldt et al., 2000).

\section{Chagas disease awareness in the United States}

While an understanding of the vector's range is important for disease control, ultimately it is physi- cians' awareness of a disease that is crucial for detecting its emergence. We combined the GIS analysis with a physician survey to have a more complete understanding of emergence potential. The diagnosis of only six human autochthonous cases in the United States roughly corresponds to periods in which there was a considerable increase in Chagas disease research and publication (Coutinho, 1999). This relationship suggests that the perceived low risk currently associated with Chagas disease in the United States is more likely due to a lack of awareness than it is a lack of actual threat. Chagas disease is not always considered as a diagnosis; physicians state that the symptoms presented in the acute stage are often misdiagnosed, and that the differential diagnosis does not consider Chagas disease unless there is a strong indication (Holbert et al., 1995). Diagnosis can be further complicated if the vector's bite is not recognized as a triatomine bite; the bite is reportedly painless and often misdiagnosed as a bite from another arthropod or a spider (Vetter, 2001). Reports such as these indicate a need to investigate awareness of the disease among physicians in the United States. If physicians and the public are not aware of the potential disease threat, the possibility for misdiagnosis is greater and cases will go undiagnosed.

Additionally, physician awareness of the various transmission routes is an important component in diagnosis. In particular, Kirchhoff et al. (2006) found that even when four recipients of infected blood demonstrated acute symptoms of Chagas disease, the physicians failed to make the diagnosis. Consequently, the oversight was attributed to mild symptoms and the physicians' lack of awareness with respect to Chagas disease transmission through blood transfusion (Kirchhoff et al., 2006). The blood supply in the United States is vulnerable to T. cruzi contamination due to an increasing Latin American population emigrating from countries where Chagas disease is endemic (Kirchhoff et al., 1987, 2006; Kirchhoff, 1993; Leiby et al., 2002; Beard et al., 2003), even though screening of blood for Chagas disease will begin soon in the United States (CDC, 2006; Lee, 2006). 


\section{Materials and methods}

\section{Delineating the range of increased triatomine activity}

The data used to delineate the range of increased triatomine activity and the area at highest risk of disease emergence include information regarding T. protracta activity threshold levels from the entomological literature, minimum temperature data, and census data for the United States. Sjogren and Ryckman (1966) outlined thresholds for increased triatomine activity, which are utilized in this study to delineate the range where the triatomine is most active and therefore creates a higher risk for the emergence of Chagas disease. The minimum threshold for increased triatomine activity is $19^{\circ} \mathrm{C}\left(67^{\circ} \mathrm{F}\right)$ (Sjogren and Ryckman, 1966).

Gridded average (1971-2000) minimum temperature data, based on the parameter-elevation regressions on independent slopes model (PRISM) (Spatial Climate Analysis Service, 2006), were acquired for the months of June, July, and August based upon accounts of increased triatomine activity in warmer temperatures, and the tendency for those months to be the hottest of the year in the United States (Sjogren and Ryckman, 1966; Wood and Wood, 1967). The 800-meter resolution temperature dataset is at an appropriate scale given the broad, country-wide scope of the project. Other climate variables, specifically humidity, wind speed, and precipitation, were considered but not included in the study given that Sjogren and Ryckman (1966) found that they had no relationship on the flight of T. protracta. The potential future range of increased triatomine activity is examined based upon the prediction of a $1^{\circ} \mathrm{C}\left(1.8^{\circ} \mathrm{F}\right)$ temperature increase by 2030 (IPCC, 2001). The use of this predicted temperature increase is based upon a report by the Intergovernmental Panel on Climate Change (IPCC) (2001) that is derived from expert collaborations and the assimilation of numerous climate models. While the temperature increase may vary locally, the predicted global mean average temperature increase is used for the purposes of this broad-scale study.
In order to calculate the population at risk under current and warmer climate conditions, we acquired 1-kilometer raster grids depicting census data for the continental United States from the Socioeconomic Data and Applications Center (SEDAC, 2007). To depict the proximity of the reported triatomine samples and the six autochthonous cases to the densely populated areas within the United States, a gridded nightlights layer was obtained from NOAA's Defense Meteorological Satellite Program (NOAA-NGDC, 2007).

The minimum temperature data values for the defined months were entered into a GIS and reclassified based on the triatomine activity threshold information. All values $>19^{\circ} \mathrm{C}\left(67^{\circ} \mathrm{F}\right)$ were assigned a value of 1 , and all other values were assigned a value of 0 . Next, we employed a raster-to-polygon conversion for each reclassified layer representing the months of June, July, and August. The same process of reclassification and conversion was then applied using the predicted $1^{\circ} \mathrm{C}\left(1.8^{\circ} \mathrm{F}\right)$ increase in temperature so as to illustrate the potential triatomine range for each month under warmer climate conditions.

Finally, we incorporated the SEDAC population density data into the GIS using an overlay analysis. The spatial analyst zonal statistics tool in ArcGIS (ESRI, 2005) was utilized to establish the population at higher risk due to increased triatomine activity. By incorporating the June, July, and August polygons for 2000 and 2030 into spatial analyst as individual datasets, we established the population at higher risk of Chagas disease transmission for both time periods and each month. To analyze the area contained within the higher risk range for 2000 and 2030 we performed a field calculation for area within the June, July, and August polygons.

\section{Evaluating disease awareness}

The results of the geospatial analysis delineating the geographic areas at higher risk informed the second portion of our study, which evaluated the level of Chagas disease awareness among physicians 
working in the higher-risk areas; it is through physicians' diagnosis that disease emergence will be recognized. In preparation for the survey, we consulted two medical professionals along with past physician surveys for procedural and content advice (Tambor et al., 1993; Bowen et al., 2005). The survey consisted of a vignette depicting a patient with typical symptoms of Chagas disease and general background questions on the canvassed physicians. The underlying purpose of the survey (to evaluate Chagas awareness) was not disclosed to the participants. Three versions of the vignette were used, and all were identical in every way except for the ethnicity of the patient (African American, Caucasian, and Hispanic). The online survey was tested using a pilot study with three physician participants, and an invitation to participate in the final survey was sent to 300 physicians. We recruited physician participants using information gathered from online searches of hospitals within the following cities/county, all of which have a population over 50,000 and are within the potential range of the vector: Corpus Christi, Texas; Modesto, California; Rutherford County, Tennessee; Jackson, Mississippi; and Santa Fe, New Mexico. These areas were selected because three of the Chagas disease cases in the United States were discovered in or around them, and/or they represent locations within the area at higher risk for disease transmission.

We sent 20 surveys of each ethnicity to physicians in the five participating cities, which totaled 60 physician surveys per city. Each physician was asked to read the vignette and then make an initial diagnosis by ranking ten of eleven diseases/health problems listed according to their likelihood for diagnosis, along with the lab studies or tests they would order to further evaluate the patient. The physicians' personal information, such as: ethnicity and gender; commonly read journals; specialty and geographic location of the practice; patient base; and when/where they received their professional education was also requested. Follow-up reminders were sent to those physicians who did not initially complete the survey.
Statistical analyses were used to determine if a significant difference exists in diagnosis depending on the ethnicity of the patient described in the vignette. A one-tailed Fisher's exact test using the VassarStats website was found to be the best test for this analysis (Lowry, 2007); in order to perform the preferred chi-square test, $80 \%$ of the cell values must be greater than or equal to 5 (Marks, 1989), and our data did not meet this requirement.

Under the null hypothesis, the proportion of physicians that considered Chagas disease based upon a specific patient ethnicity is equal to the proportion of physicians who considered Chagas disease based upon a patient of another ethnicity. Under the alternative hypothesis, the proportion of physicians ranking Chagas disease in differential diagnosis is not identical with respect to ethnicity. Other survey information regarding lab studies/tests and the physicians' background information provided in the survey was analyzed qualitatively.

\section{Results}

Areas of increased risk of Chagas disease transmission

The overlay analysis of the gridded nightlights layer delineating populated areas within the United States with triatomine samples illustrates the vector's proximity to these areas (Fig. 2). Samples have been collected in or near heavily populated areas of southern California, northern Utah, Missouri, central Tennessee, northern Georgia, southern Texas, and Florida. Despite the sizeable triatomine range depicted in Figure 2, only certain areas within the United States are considered at higher risk for Chagas disease transmission based upon warmer temperatures, which increase triatomine activity and increase the likelihood of contact with humans.

The areas predicted to be at increased risk under current and predicted temperature conditions are shown in Figure 3. In Figure 3A, the June 2000 range at higher risk covers a small portion of the southwestern United States and much of the south- 


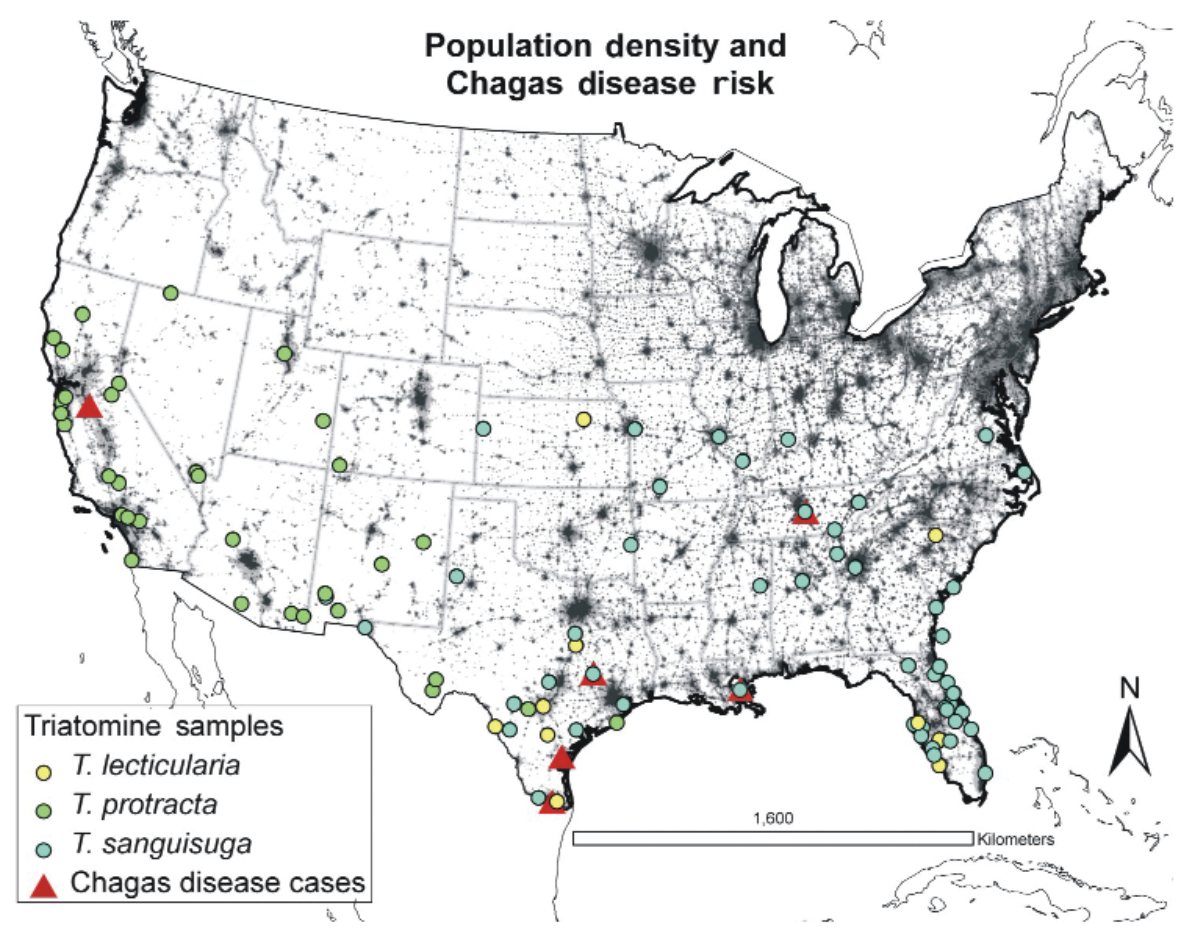

Fig. 2. Triatomine samples and autochthonous Chagas disease cases and their proximity to populated areas in the United States. Data sources: Usinger, 1944; Woody and Woody, 1955; Anonymous, 1956; Sjogren and Ryckman, 1966; Lent and Wygodzinsky, 1979; Betz et al., 1984; Ryckman, 1984; Schiffler et al., 1984; Navin et al., 1985; Ochs et al., 1996; Bradley et al., 2000; Herwaldt et al., 2000; Yabsley and Noblet, 2002; ESRI, 2005; NOAA-NGDC, 2007.

central and southeastern portion of the country. A small area in southern California, Nevada, and the southern half of Arizona are at increased risk, along with most of Texas (except the extreme western portion and the panhandle), and the southern half of Oklahoma across to the eastern coast of the United States. By July, the range of higher risk expands into southern Utah, and also expands to the north in the Midwest and eastern United States (Fig. 3B). Finally, the current higher risk range contracts between July and August primarily in the central United States, and by August (Fig. 3C) only covers a portion of Kansas and excludes Missouri and Illinois. The areas of higher elevation across the southern United States, including the southern Rocky Mountains and the southern Appalachians, are excluded from the higher risk areas in all months.

The population at increased risk grows considerably between June and July, and decreases some- what between July and August (Fig. 4). This is directly tied to the relatively large temperature increase between the months of June and July, and a slight temperature decrease into the month of August. Between July and August, the eastern coast does not experience as much of a decrease in higher risk as does the central United States. Consequently, the larger population found on the eastern coast may explain why there is only a slight decrease in affected population for the month of August for the country as a whole (Fig. 4).

For each of the three months, the area at increased risk for Chagas disease transmission expands under the predicted $1^{\circ} \mathrm{C}\left(1.8^{\circ} \mathrm{F}\right)$ temperature increase, although the expansion varies from month to month. For the month of June, the higher risk region expands in area by $23 \%$ between 2000 and 2030; this percentage increase is noticeably higher than the increase for July and August, which is $15 \%$ 

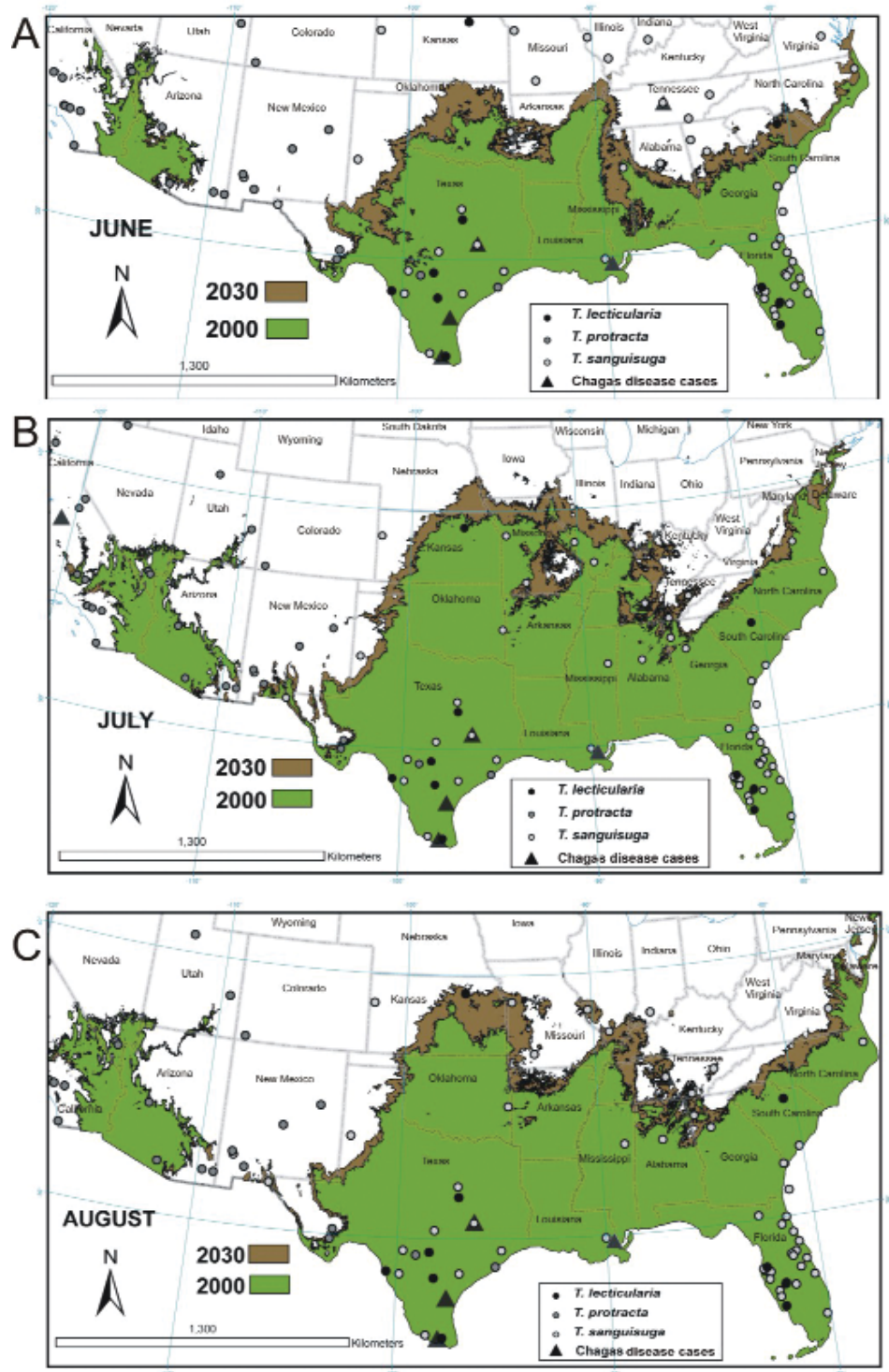

Fig. 3. Areas of increased risk of Chagas disease transmission. Data sources: ESRI, 2005; Spatial Climate Analysis Service, 2006.

and $16 \%$, respectively. As is evident from Figure 3, the range at higher risk due to a temperatureinduced increase in triatomine activity will expand northward in the Midwest and north along the Atlantic coast, placing a considerably larger population in the higher risk range for disease transmission. The area affected by increasing temperatures between 2000 and 2030 illustrates the impact of predicted climate change on vector-borne disease transmission and reveals a need for ongoing studies to prevent or control disease emergence.

\section{Spatial pattern validation}

Given that this study evaluated the potential for Chagas disease emergence in the United States, a database of cases does not exist for model validation and so we utilized two other forms of model valida- 
United States' population affected by increased triatomine activity

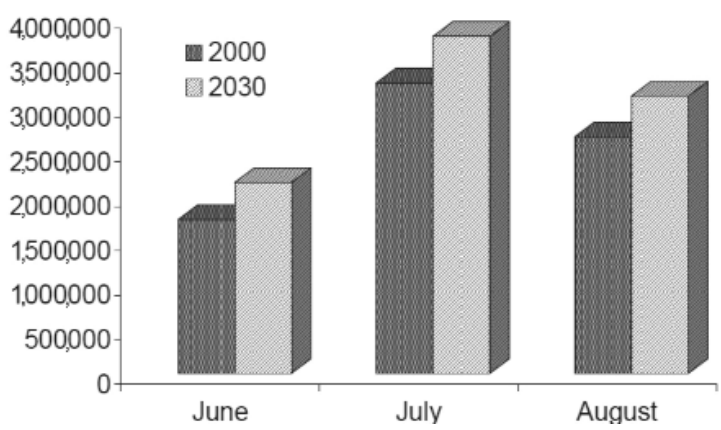

Fig. 4. Population at higher risk for Chagas disease transmission due to climate change (SEDAC, 2007).

tion in order to evaluate the accuracy and usefulness of the model (Rykiel, 1996). The first validation compares our results to the findings from an ecological niche model (GARP) and the second validation compares our results with the location of the six autochthonous cases of Chagas disease in the United States. The results of the GARP model, which focused on the south-central portion of the United States, depicts the T. gerstaeckeri range as covering the southwestern portion of Texas, extending into the panhandle and the southeastern corner of New Mexico (Beard et al., 2003). The range depicted in the GARP model overlaps our results through the southeastern tip of New Mexico and southwestern Texas; however, the maps differ where the GARP model's range extends further north through the Texas panhandle and southeastern New Mexico. This difference is likely due to our use of an increased activity threshold for the vector, whereas the GARP model is based solely upon the vector's distribution.

The six autochthonous cases in the United States, while representing a small sample, serve as the second form of validation of our model. A comparison of case location with the area defined at increased risk in this study reveals that five of the six autochthonous cases in the United States occurred within the area currently delineated as higher risk for disease transmission. All point data representing the five diagnosed cases are within the 2000 range for both July and August except for the case from Lake Don Pedro, California, which is not depicted in the defined higher risk range for June, July, or August. We recognize in this study that the vector is likely to be present outside of the area that we define as "higher risk"; however, our goal is to define areas where the risk of transmission is greater due to increased vector activity at warmer temperatures.

\section{Physician awareness of Chagas disease in the United States}

Of the 300 physicians canvassed for this study, there was only a $7 \%$ response rate. This lackluster response limits quantitative analysis; however, through the use of a contingency table and the Fisher's exact test, we were able to establish a measure of statistical significance based upon the patient's race/ethnicity described in the vignette. Of the 22 physicians who responded to the survey, eight ranked Chagas disease as a potential diagnosis and 14 did not. Among those who ranked Chagas disease, four were based upon the Hispanic vignette, and four were not. The four that were not based upon the Hispanic vignette consisted of three for the Caucasian patient and one for the African American patient, neither of which were statistically significant. Among the 14 physicians not ranking Chagas disease as a potential diagnosis, one was based upon the Hispanic patient and 13 were not. The Fisher's exact test reveals a P-value of 0.039 . This statistically significant value $(\alpha=0.05)$ indicates that physicians practicing within the range at higher risk for Chagas disease, as defined by the GIS analysis, are more likely to consider Chagas disease in differential diagnosis of Hispanic patients than for either Caucasian or African-American patients.

Qualitative analysis reveals that travel history is a concern for some physicians. Fourteen percent of participating physicians requested information on the patients' travel history alone, indicating recognition that travelers can be responsible for the introduction of disease agents. In one case, Chagas dis- 
ease is specifically written next to the statement indicating the need for travel history, and another participant states that he or she "must know geography or travel history to prioritize infectious etiologies." These data are valuable to further illustrate that Chagas disease is not always considered as a possible diagnosis in the areas defined to be at increased risk in the United States. Physician ethnicity or education information did not appear to be a factor in the survey results.

\section{Discussion}

Using the frameworks of disease ecology and landscape epidemiology with a broad-scale geographical approach, this study has examined the potential for Chagas disease to emerge in the United States. Specifically, areas at higher risk for Chagas disease emergence were identified based on temperature conditions using GIS analyses, and within the high risk range, the survey analysis indicates that a lack of physician awareness contributes to disease emergence potential. While the sylvatic nature and delayed defecation exhibited in triatomine species within the United States indicate a relatively low risk of Chagas disease transmission, there is clearly the potential for emergence given evidence of increased triatomine domesticity (Beard et al., 2003), appropriate climate conditions for triatomine activity, and a general lack of awareness among physicians when considering Chagas as a potential diagnosis. While previous research suggests that the northern limit of the triatomine range in the United States currently extends beyond 40 degrees north latitude, the study presented here indicates that the risk of Chagas disease transmission is highest in the lower latitudes in the southern portion of the country.

The results presented here fill an important gap in our understanding of the emergence and management of Chagas disease in the United States. In an applied sense, our study has identified areas where we should focus public health resources for vector control and outbreak prevention. The study has also shown that there is a need to raise awareness levels about the disease among health care professionals, particularly those within the high-risk area.

Limitations of the study are related to differing opinions about the classification of triatomine species, selection of the utilized threshold data, and the use of 2000 census data in predictive mapping. Due to the broad-scale approach used in this study, we believe the general argument is sound in spite of these limitations. Nevertheless, future fine-scale studies of Chagas disease in the United States should factor in these limitations as well as additional variables that pertain to the specific region of study and the particular triatomine species present.

Ryckman (1984) indicates that the lack of taxonomic information on triatomines has led to conflicting scientific conclusions about the species' distribution. Threshold data is frequently difficult to obtain and oftentimes reports vary. Uncertainty may arise due to the application of the $19^{\circ} \mathrm{C}\left(67^{\circ} \mathrm{F}\right) \mathrm{min}$ imum threshold to the three species highlighted in this study when, in fact, the threshold data are based solely on T. protracta because of the dearth of information on other species (Sjogren and Ryckman, 1966). Finally, the gridded population data are based on the 2000 census, and when considering the population at risk under warmer temperatures, population growth and the movement of people is not taken into account. With respect to the physician survey, a larger response would increase the power of statistical analyses and allow for more extensive conclusions to be drawn on the consideration of Chagas disease as a diagnosis. Conducting a local survey as part of a fine-scale study may increase the participation rate. Nevertheless, the results of this study offer a different perspective with which to investigate broad-scale disease potential, and also elucidate the need for future research in order to improve our understanding of the ways in which environmental conditions and physician awareness can interact in disease emergence.

Reports that triatomine contact with domestic dogs presents an increased risk of Chagas disease transmission to humans points toward the need for increased collaboration between epidemiologists, 
entomologists, and veterinarians in future disease risk predictions (Barr et al., 1995; Bradley et al., 2000; Beard et al., 2003; Enger et al., 2004; Crisante et al., 2006). The results presented here might serve as insight for comprehensive fine-scale studies of areas that are in the margins of the defined higher-risk ranges through a GIS model that utilizes weighted variables acquired from landscape, ecological, and environmental data. In addition, as the T. cruzi infected population grows through international migration and the close proximity of triatomines to people becomes greater, it is necessary to study the risk of disease transmission within the high-risk area. Finally, the results of this study show a clear need to further evaluate Chagas disease as a potential diagnosis among physicians and healthcare providers given the important role they play in the early detection of emerging diseases.

In order to maintain an able-bodied society, it is necessary to direct public health resources towards present health threats as well as emerging diseases such as Chagas disease. The factors of triatomine biogeography and Chagas disease awareness characterize the regions at higher risk for Chagas disease emergence in the United States, and justify a need for in-depth investigation so as to alleviate the potential for disease emergence. In order to prevent or control vector-borne disease epidemics, it is first necessary to delineate areas at highest risk for transmission, followed by the implementation of a plan of action that includes educating both the general population and public health officials about the disease risk and methods for controlling the vector.

\section{Acknowledgements}

We thank M.D., Ph.D. student, Matthew Collins, and Dr. Nelson Lezcano for their help in development of the survey, along with Amy Willis Amara, M.D., Ph.D., Chadwick Hales, M.D., Ph.D. and Brent Steadman, M.D., Ph.D. for participating in the pilot study. Special thanks go to the physicians who participated in the survey. The authors also acknowledge the helpful reviewer and editor suggestions that improved this manuscript. This research is funded by the
Department of Geography in the College of Natural Resources at Virginia Polytechnic Institute and State University.

\section{References}

Abad-Franch F, Paucar CA, Carpio C, Cuba Cuba CA, Aguilar VHM, Miles MA, 2001. Biogeography of Triatominae (Hemiptera: Reduviidae) in Ecuador: implications for the design of control strategies. Mem Inst Oswaldo Cruz 96, 611-620.

Anonymous, 1956. Found: two cases of Chagas disease. Texas Health Bull 9, 11-13.

Barr SC, Van Beek O, Carlisle-Nowak MS, Lopez JW, Kirchhoff LV, Allison N, Zajac A, de Lahunta A, Schlafer DH, Crandall WT, 1995. Trypanosoma cruzi infection in walker hounds from Virginia. Am J Vet Res 56, 1037-1044. Beard CB, Pye G, Steurer FJ, Rodriguez R, Campman R, Peterson AT, Ramsey J, Wirtz RA, Robinson LE, 2003. Chagas disease in a domestic transmission cycle, Southern Texas, USA. CDC Emerg Infect Dis 9, 103-105.

Betz TG, Hnilica VS, Smith JH, Hansan W, Reiger L, Ohngley D, Davis BL, Allain D, Steurer F, Walis K, 1984. Chagas disease investigation. Texas Prev Dis News 31, 1-4. Bowen J, Pheby D, Charlett A, McNulty C, 2005. Chronic fatigue syndrome: a survey of GPs' attitudes and knowledge. Fam Pract 22, 389-393.

Bradley KK, Bergman DK, Woods JP, Crutcher JM, Kirchhoff LV, 2000. Prevalence of American trypanosomiasis (Chagas disease) among dogs in Oklahoma. J Am Vet Med Assoc 217, 1853-1857.

Bustamante DM, Monroy MC, Rodas AG, Juarez JA, Malone JB, 2007. Environmental determinants of the distribution of Chagas disease vectors in south-eastern Guatemala. Geospatial Health 2, 199-211.

CDC, 2006. Chagas disease fact sheet. Division of parasitic diseases, parasitic disease information. www.cdc.gov/ncidod/ dpd/parasites/chagasdisease/factsht_chagas_disease.htm.

Cooke FJ, Shapiro DS, 2003. Global outbreak of severe acute respiratory syndrome (SARS). Int J Infect Dis 7, 80-85.

Costa J, Peterson AT, Beard CB, 2002. Ecologic niche modeling and differentiation of populations of Triatoma brasiliensis neiva, 1911, the most important Chagas' disease vector in northeastern Brazil (Hemiptera, Reduviidae, 
Triatominae). Am J Trop Med Hyg 67, 516-520.

Coutinho M, 1999. Ninety years of Chagas disease: a success story at the periphery. Soc Stud Sci 29, 519-549.

Crisante G, Rojas A, Teixeira MMG, Añez N, 2006. Infected dogs as a risk factor in the transmission of human Trypanosoma cruzi infection in western Venezuela. Acta Trop 98, 247-254.

Dorn PL, Perniciaro L, Yabsley MJ, Roellig DM, Balsamo G, Diaz J, Wesson D, 2007. Autochthonous transmission of Trypanosoma cruzi, Louisiana. Emerg Infect Dis 13, 605-607.

Enger KS, Ordoñez R, Wilson ML, Ramsey JM, 2004. Evaluation of risk factors for rural infestation by Triatoma pallidipennis (Hemiptera: Triatominae), a Mexican vector of Chagas disease. J Med Entomol 41, 760-767.

Epstein PR, Diaz HF, Elias S, Grabherr G, Graham NE, Martens WJM, Mosley-Thompson E, Susskind J, 1998. Biological and physical signs of climate change: focus on mosquito-borne diseases. Bull Am Met Soc 79, 409-417.

ESRI, 1985. Software Arc-GIS version 9.1. ESRI, Redlands, CA, USA.

Guzman-Tapia Y, Ramirez-Sierra MJ, Escobedo-Ortegon J, Dumonteil E, 2005. Effect of hurricane Isidore on Triatoma dimidiata distribution and Chagas disease transmission risk in the Yucatán peninsula of Mexico. Am J Trop Med Hyg 73, 1019-1025.

Haggett P, 1994. Geographical aspects of the emergence of infectious diseases. Geografiska Annaler 76, 91-104.

Herwaldt BL, Grijalva MJ, Newsome AL, McGhee CR, Powell MR, Nemec DG, Steurer FJ, Eberhard ML, 2000. Use of polymerase chain reaction to diagnose the fifth reported US case of autochthonous transmission of Trypanosoma cruzi, in Tennessee, 1998. J Infect Dis 181, 395-399.

Holbert RD, Magiros E, Hirsch CP, Nunenmacher SJ, 1995. Chagas' disease: a case in South Mississippi. J Miss State Med Assoc 36, 1-5.

IPCC, 2001. Climate change 2001: the scientific basis - technical summary of the working group I report. Edited by JT Houghton, Y Ding, DJ Griggs, M Noguer, PJ van der Linden, X Dai, K Maskell, CA Johnson. Third assessment report of the Intergovernmental Panel on Climate Change. Cambridge, UK, Cambridge University Press, 70 p.

Kagan IG, Norman L, Allain D, 1966. Studies on Trypanosoma cruzi isolated in the United States: a review.
Rev Biol Trop 14, 55-73.

Kirchhoff LV, 1993. American trypanosomiasis (Chagas' disease) - a tropical disease now in the United States. N Eng J Med 329, 639-644.

Kirchhoff LV, Gam AA, Gilliam FC, 1987. American trypanosomiasis (Chagas' disease) in Central American immigrants. Am J Med 82, 915-920.

Kirchhoff LV, Paredes P, Lomelí-Guerrero A, Paredes-Espinoza M, Ron-Guerrero CS, Delgado-Mejía M, Peña-Muñoz JG, 2006. Transfusion-associated Chagas disease (American trypanosomiasis) in Mexico: implications for transfusion medicine in the United States. Transfusion 46, 298-304.

Lee K, 2006. Medicare: hospital outpatient prospective payment system and CY 2007. Payment rates; proposed rule (Docket \# CMS-1506-P). American Red Cross letter to the centers for medicare and medicaid services dated October $10,2006$.

Leiby DA, Herron Jr. RM, Read EJ, Lenes BA, Stumpf RJ, 2002. Trypanosoma cruzi in Los Angeles and Miami blood donors: impact of evolving donor demographics on seroprevalence and implications for transfusion transmission. Transfusion 42, 549-555.

Leiby DA, Rentas FJ, Nelson KE, Stambolis VA, Ness PM, Parnis C, McAllister HA, Yawn DH, Stumpf RJ, Kirchhoff LV, 2000. Evidence of Trypanosoma cruzi infection (Chagas' disease) among patients undergoing cardiac surgery. Circulation 102, 2978-2982.

Lent H, Wygodzinsky P, 1979. Revision of the Triatominae (Hemiptera, Reduviidae), and their significance as vectors of Chagas' disease. Bull Am Mus Nat His 163, 123-520.

López-Cárdenas J, Gonzalez Bravo FE, Salazar Schettino PM, Gallaga Solorzano JC, Ramírez Barba E, Martinez Mendez J, Sánchez-Cordero V, Peterson AT, Ramsey JM, 2005. Fine-scale predictions of distributions of Chagas disease vectors in the state of Guanajuato, Mexico. J Med Entomol 42, 1068-1081.

Lowry R, 2007. VassarStats: web site for statistical computation. http://faculty.vassar.edu/lowry/VassarStats.html.

Marks R, 1989. Analyzing research data. The basics of biomedical research methodology. Melbourne, FL, Robert E. Kreiger Publishing Co.

Meade MS, Earickson RJ, 2005. Medical Geography. Second ed. New York, The Guilford Press.

Monroy MC, Bustamante DM, Rodas AG, Enriquez ME, 
Rosales RG, 2003. Habitats, dispersion and invasion of sylvatic Triatoma dimidiata (Hemiptera: Reduviidae: Triatominae) in Petén, Guatemala. J Med Entomol 40, 800806.

Navin TR, Roberto RR, Juranek DD, Limpakarnjanarat K, Mortenson EW, Clover JR, Yescott RE, Taclindo C, Steurer F, Allain D, 1985. Human and sylvatic Trypanosoma cruzi infection in California. Am J Public Health 75, 366-369.

NOAA-NGDC EOG, 2007. Nightlights. Boulder, CO: Defense Meteorological Satellite Program. http://www.ngdc.noaa.gov/ dmsp/download.html.

Ochs DE, Hnilica VS, Moser DR, Smith JH, Kirchhoff LV, 1996. Postmortem diagnosis of autochthonous acute chagasic myocarditis by polymerase chain reaction amplification of a species-specific DNA sequence of Trypanosoma cruzi. Am J Trop Med Hyg 54, 526-529.

Peterson AT, Sánchez-Cordero V, Beard CB, Ramsey JM, 2002. Ecologic niche modeling and potential reservoirs for Chagas disease, Mexico. Emerg Infect Dis 8, 662-667.

Ryckman RE, 1984. The Triatominae of North and Central America and the West Indies: a checklist with synonymy (Hemiptera: Reduviidae: Triatominae). Bull Soc Vector Ecol 9, 71-83.

Rykiel JEJ, 1996. Testing ecological models: the meaning of validation. Ecol Modell 90, 229-244.

Schiffler RJ, Mansur GP, Navin TR, Limpakarnjanarat K, 1984. Indigenous Chagas' disease (American trypanosomiasis) in California. JAMA 251, 2983-2984.

Schofield CJ, 1979. The behaviour of Triatominae (Hemiptera: Reduviidae): a review. Bull Entomol Res 69, 363-379.

SEDAC, 2007. CIESIN, Center for international Earth science information network, SF1 Census Data, http://sedac.ciesin.columbia.edu/usgrid/downloads.jsp.

Sjogren RD, Ryckman RE, 1966. Epizootiology of Trypanosoma cruzi in Southwestern North America. Part VIII: nocturnal flights of Triatoma protracta (Uhler) as indicated by collections at black light traps. J Med Entomol 3, 81-92.

Spatial Climate Analysis Service, 2006. PRISM Group. Oregon State University Average Minimum Temperature Normals, 1971-2000. http://www.prismclimate.org. Map created 02/28/2007.

Tambor ES, Chase GA, Faden RR, Geller G, Hofman KJ,
Holtzman NA, 1993. Improving response rates through incentive and follow-up: the effect on a survey of physicians' knowledge of genetics. Am J Public Health 83, 1599-1603.

Usinger RL, 1944. The Triatominae of North and Central America and the West Indies and their public health significance. Public Health Bulletin No. 288, Ed. U.S.P.H. Service: U.S. Government Printing Office.

Vazquez-Prokopec GM, Ceballos LA, Kitron U, Gürtler RE, 2004. Active dispersal of natural populations of Triatoma infestans (Hemiptera: Reduviidae) in rural Northwestern Argentina. J Med Entomol 41, 614-621.

Vazquez-Prokopec GM, Ceballos LA, Marcet PL, Cecere MC, Cardinal MV, Kitron U, Gürtler RE, 2006. Seasonal variations in active dispersal of natural populations of Triatoma infestans in rural north-western Argentina. Med Vet Entomol 20, 273-279.

Vetter R, 2001. Kissing bugs (Triatoma) and the skin. Dermatol Online J 7: 6 .

Wood SF, 1938. A new locality for Trypanosoma cruzi Chagas in California. Science 87, 366-367.

Wood SF, Wood FD, 1967. Ecological relationships of Triatoma p. protracta (Uhler) in Griffith Park, Los Angeles, California. Pacific Insects 9, 537-550.

Woody NC, Woody HB, 1955. American trypanosomiasis (Chagas' disease): first indigenous case in the United States. J Am Med Assoc 159, 676-677.

Yang GJ, Vounatsou P, Tanner M, Zhou ZN, 2006. Remote sensing for predicting potential habitats of Oncomelania hupensis in Hongze, Baima and Gaoyou lakes in Jiangsu province, China. Geospatial Health 1, 85-92.

Yabsley MJ, Noblet GP, 2002. Seroprevalence of Trypanosoma cruzi in raccoons from South Carolina and Georgia. J Wildlife Dis 38, 75-83.

Zayas CF, Perlino C, Calideno A, Jackson D, Martinez EJ, Tso P, Heffron TG, Logan JL, Herwaldt BL, Moore AC, Steurer FJ, Bern C, Maguire JH, 2001. Chagas disease after organ transplantation - United States, 2001. CDC Morbidity and Mortality Weekly Report 51, 210-212.

Zeledón R, 1974. Epidemiology, modes of transmission, and reservoir hosts of Chagas disease. In: Trypanosomiasis and leishmaniasis with special reference to Chagas disease. K Elliott, M O'Connor and GF Wolstenholme (eds). Amsterdam, Associated Scientific Publishers, pp. 51-85. 